\title{
Influência da freqüência de ordenhas diárias sobre a eficiência produtiva de vacas mestiças Holandês-Zebu e o desempenho dos seus bezerros ${ }^{1}$
}

\section{José Reinaldo Mendes Ruas ${ }^{2}$, Felipe Zandonadi Brandão ${ }^{3}$, José Monteiro da Silva Filho ${ }^{4}$, Álan Maia Borges ${ }^{4}$, Bruno Campos de Carvalho ${ }^{5}$, Arismar de Castro Menezes ${ }^{6}$, Reginaldo Amaral $^{6}$, Alberto Marcatti Neto ${ }^{6}$}

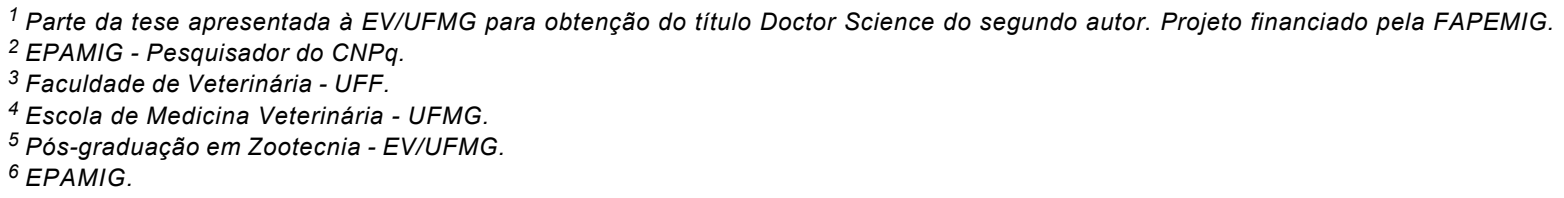

RESUMO - Verificou-se a influência do número de ordenhas diárias sobre a produção de leite, a duração da lactação, a incidência de mastite e o desempenho dos bezerros. Foram utilizadas 63 vacas primíparas e multíparas mestiças (HolandêsZebu) com boa condição corporal ao parto, distribuídas ao acaso, por meio de sorteio, em três grupos experimentais com número igual de repetições, representadas pelo número de ordenhas diárias: vacas ordenhadas uma vez por dia; vacas ordenhadas duas vezes ao dia; vacas ordenhadas alternadamente a cada 14 dias, uma ou duas vezes ao dia. A saúde da glândula mamária não foi influenciada pela diminuição do número de ordenhas diárias. Não houve efeito do número de ordenhas sobre o desempenho dos bezerros, mesmo daqueles submetidos a uma mamada diária. A duração da lactação não foi influenciada pela adoção de duas ordenhas diárias. A adoção da segunda ordenha diária aumentou em $24,54 \%$ a produção de leite de vacas com potencial produtivo para 2.500 a $2.800 \mathrm{~L}$ por lactação.

Palavras-chave: Bos taurus x Bos indicus, ganho de peso, número de ordenhas, peso do bezerro, produção de leite

\section{Effect of milking frequency on production of crossbred holstein-zebu cows}

\begin{abstract}
This trial was conducted to study the effects of daily milking frequency on milk yield, duration of lactation, incidence of mastitis, and calves body weight gain. Sixty-three crossbred Holstein-Zebu cows were equally and randomly assigned to three experimental groups according to the frequency of daily milkings as follows: once a day milking, twice a day milking, or alternating once or twice a day milking every 14 days. The duration of lactation, mammary gland health, and calf production did not differ among treatments in this study. However, cows milked twice a day yielded $24.54 \%$ more milk per lactation $(699.9 \mathrm{~kg})$ compared to the other milking regimes.
\end{abstract}

Key Words: calf weight, crossbred cows, daily milking, milk yield, weight gain

\section{Introdução}

O aumento do consumo de leite pela população provocou incremento substancial no agronegócio do leite. Esta demanda poderia ser atendida com o aumento da quantidade de concentrado por vaca ou do número de animais no rebanho. Entretanto, as duas opções significam aumento do custo de produção e grandes investimentos na compra de animais e em infra-estrutura. Outra possibilidade aos produtores seria o aumento do número diário de ordenhas (Amos et al., 1985), capaz de aumentar a produção e, em conseqüentemente, a receita do produtor. Entretanto, acarreta aumento dos gastos com alimentação, mão-de-obra, maquinário de ordenha e implementos utilizados na ordenha - soluções desinfetantes, papel toalha, água, entre outros (Erdman \& Varner, 1995).

A produção de leite em vacas leiteiras está positivamente correlacionada à freqüência de ordenhas (Knight \& Dewhurst, 1994). Quando o número de ordenhas diárias passa de duas para três vezes, a produção de leite aumenta de 6 a $25 \%$. Em sistemas de duplo propósito, a produção de leite em fêmeas amamentando e ordenhadas aumenta de 7 a 20\% (Bar-Peled et al., 1995). Erdman \& Varner (1995) compilaram dados de 20 trabalhos científicos e observaram que a utilização de três ordenhas diárias provocou aumento de $3,5 \mathrm{~kg} /$ dia de leite, em relação a duas ordenhas.

As células secretoras presentes nos alvéolos produzem proteína de baixo peso molecular, que, de forma autócrina, 
regula a secreção do leite (FIL - feedback inhibitor of lactation). O efeito da freqüência de ordenhas sobre a produção de leite é promovido pela quantidade desta proteína inibidora no interior do alvéolo. Assim, quando se aumenta o número de ordenhas, passando de uma para duas ou de duas para três ordenhas, ocorre maior esgotamento da glândula mamária, acompanhado de menor concentração da proteína inibidora no interior dos alvéolos, permitindo maior produção de leite. Ao reduzir o número de ordenhas diárias, observa-se maior quantidade desta proteína, que irá determinar uma inibição da secreção do leite (Knight \& Dewhurst, 1994; Bar-Peled et al., 1995). Acredita-se também que o aumento da pressão intra-alveolar, decorrente da produção de leite e do não-esgotamento adequado da glândula mamária, pode contribuir para a redução da produção (Knight et al., 1992). Esta proteína inibidora é ativa no leite estocado no tecido secretor, mas não no leite presente na cisterna. Conseqüentemente, vacas que apresentam cisternas com maior capacidade são mais tolerantes ao manejo de uma ordenha que aquelas com cisternas menores (Knight \& Dewhurst, 1994).

DePeters et al. (1985) avaliaram o efeito do aumento do número diário de ordenhas (de duas para três) em vacas primíparas e pluríparas durante toda a lactação. A ordenha três vezes ao dia aumentou a produção de leite nas vacas pluríparas e primíparas em 15 e $6 \%$, respectivamente. $\mathrm{O}$ consumo de matéria seca não diferiu entre os tratamentos, embora as vacas ordenhadas três vezes tenham ganhado menos peso que as ordenhadas duas vezes, por entrarem em balanço energético negativo.

Hillerton et al. (1990) observaram os efeitos do aumento do número de ordenhas diárias sobre a glândula mamária, em estudo com vacas da raça Holandesa, no qual todos os quartos da glândula mamária foram ordenhados duas vezes ao dia, durante 14 dias, e após este período, dois quartos contralaterais passaram a ser ordenhados quatro vezes ao dia. Além disso, foram coletadas amostras de leite, fazendo-se biópsias dos quartos mamários. Durante o período préexperimental, não se observou diferenças entre os quartos quanto à produção de leite. No entanto, após o início do tratamento, o aumento da freqüência de ordenhas elevou a produção de leite em $10,4 \%$. Os autores observaram que a área alveolar e o número de células secretoras por alvéolo foi maior nos quartos submetidos a quatro ordenhas diárias e concluíram que o aumento da produção pelo maior número de ordenhas resultou do aumento da proliferação e diferenciação do epitélio secretor da glândula mamária.

Knight \& Dewhurst (1994) utilizaram vacas da raça Holandesa ordenhadas duas vezes ao dia durante as 19 semanas iniciais da lactação e somente uma vez por dia na $20^{\text {a }}$ semana da lactação. No manejo de duas ordenhas diárias, a produção de leite foi de $21,21 \mathrm{~kg} / \mathrm{dia}$. A implantação de uma ordenha diária ocasionou queda de $22,8 \%$ na produção de leite, que passou a ser de $16,37 \mathrm{~kg} / \mathrm{dia}$. Após uma semana, os autores retomaram o manejo de duas ordenhas diárias e verificaram recuperação da produção de leite $(20,27 \mathrm{~kg})$. Os resultados comprovaram que a utilização de uma ordenha diária em curtos períodos no meio da lactação não afeta a persistência da lactação, ou seja, não promove involução da glândula mamária. Entretanto, esse fato não é observado quando esse manejo é adotado no início da lactação, quando a glândula está em alta atividade.

Ao compararem uma ordenha com duas ordenhas diárias, Stelwagen \& Knight (1997) observaram reduções de 28 a $38 \%$ na produção de leite. Constataram também que a redução de duas para uma ordenha diária não alterou o volume da glândula mamária, o que sugere não haver perda de células. Entretanto, a adoção de uma ordenha diária determina redução da eficiência de secreção. Além disso, os autores encontraram correlação positiva entre produção de leite e volume da cisterna da glândula quando as vacas foram ordenhadas apenas uma vez ao dia. Ferreira et al. (1996) observaram que bezerros amamentados duas vezes ao dia mostraram melhor desempenho que os amamentados uma vez ao dia.

Este experimento foi conduzido com o objetivo de estudar a influência do número de ordenhas diárias em vacas mestiças sobre a produção de leite, a duração da lactação, a incidência de mastite e o desempenho dos bezerros.

\section{Material e Métodos}

Foram utilizadas 63 vacas (Holandês $\mathrm{x}$ Zebu) primíparas $(\mathrm{n}=37)$ e multíparas $(\mathrm{n}=26)$, de graus de sangue variados (51 1/2 Holandês x $1 / 2$ Zebu; 9 3/4 Holandês x 1/4 Zebu; e $31 / 4$ Holandês $x 3 / 4$ Zebu) e divididos igualmente entre os tratamentos. As vacas foram distribuídas ao acaso, em três grupos experimentais com número igual de repetições, conforme os tratamentos (números de ordenhas diárias) (Tabela 1).

As vacas do grupo I foram ordenhadas uma vez ao dia, a partir das $6 \mathrm{~h}$; as do grupo II, duas vezes ao dia, às 6 e 14 $\mathrm{h}$; e as do grupo III, uma ou duas vezes ao dia, de forma alternada. Nos primeiros 14 dias após o parto, as vacas foram ordenhadas duas vezes ao dia e, nos 14 dias seguintes, uma vez ao dia. Os procedimentos foram alternados sucessivamente até o final da lactação e os horários das ordenhas dos grupos II e III foram iguais. 
As vacas foram mantidas em pastagens de topografia plana, formadas por capim-braquiária (Brachiaria decumbens e Brachiaria brizantha), com cochos cobertos para sal mineral, e receberam diariamente, no momento da ordenha, em cochos individualizados, concentrado con tendo $22 \%$ de proteína bruta e $75 \%$ de NDT, de acordo com a produção, de modo que, para cada $3 \mathrm{~kg}$ de leite, acima dos primeiros $8 \mathrm{~kg}$, era ofertado $1 \mathrm{~kg}$ de concentrado. No inverno, os animais receberam ad libitum silagem de milho (Zea mays, Z.) e/ou cana-de-açúcar como fonte de volumoso. Vacas com menos de 90 dias pós-parto recebiam apenas silagem de milho. Após este período, as fêmeas que apresentavam produção superior a $14 \mathrm{~kg}$ diários de leite recebiam apenas silagem de milho. Entretanto, vacas com produções de 11 a $14 \mathrm{~kg}$ de leite por dia recebiam 50\% de silagem de milho e $50 \%$ de cana de açúcar. Finalmente, as que produziam menos de $11 \mathrm{~kg}$ de leite recebiam apenas cana-de-açúcar acrescida de $1 \%$ de uréia. A suplementação com volumoso era realizada em uma pista de alimentação. No inverno, o concentrado era fornecido na mesma relação anterior, porém, após os primeiros $5 \mathrm{~kg}$ de leite produzidos.

O sistema de ordenha utilizado foi o mecânico, com o equipamento tipo balde ao pé em fosso, em linha dupla e com seis conjuntos de ordenha. Nos primeiros 90 dias pós-parto, deixou-se um teto sem ordenhar, efetuando-se a ordenha de todos os tetos. A lactação foi encerrada quando, após dois controles leiteiros consecutivos, o animal produzia menos que $3 \mathrm{~kg}$ de leite, ou quando faltavam 60 dias para o próximo parto. No momento da ordenha, o bezerro era levado à vaca, mamava e, assim que o leite descia, era retirado da sala de ordenha, iniciando-se a ordenha. Portanto, o restante da ordenha acontecia na ausência do bezerro.

As medidas de higiene utilizadas na ordenha consistiam da lavagem dos tetos com água corrente e da secagem com panos mantidos em balde com hipoclorito de sódio. O exame de CMT (California Mastitis Test) foi realizado a cada 14 dias e, nos animais com alguma alteração, era realizado

Tabela 1 - Grupos experimentais

Table 1 - Experimentalgroups

\begin{tabular}{ll}
\hline Grupo I & Vacas ordenhadas uma vez ao dia $(\mathrm{n}=21)$ \\
Group I & Cows milked once a day $(n=21)$ \\
Grupo II & Vacas ordenhadas duas vezes ao dia $(\mathrm{n}=21)$ \\
Group II & Cows milked twice a day $(n=21)$ \\
Grupo III & Vacas ordenhadas alternadamente a cada 14 dias \\
& uma vez e duas vezes ao dia $(\mathrm{n}=21)$ \\
Group III & Cows milked alternating once or twice \\
& daily every fourteen days $(n=21)$ \\
\hline
\end{tabular}

diariamente o exame de Tamis (Schalm \& Noorlander, 1957; Radostitis, 1994). De posse dos resultados do CMT, atribuiu-se um escore para cada vaca. Tetos sadios recebiam nota 1 , com reação de uma cruz, recebiam nota dois; com reação de duas cruzes, nota 3; e com reação de três cruzes, nota 4. A resultante do somatório dos quatro tetos determinou o escore para a mastite.

Do nascimento até 90 dias de idade, deixava-se um quarto da glândula mamária sem ordenhar e, após o término da ordenha, os bezerros tinham acesso às mães por um período de 30 minutos, sendo levados posteriormente aos piquetes, inclusive os das vacas ordenhadas apenas uma vez ao dia. A partir dos 90 dias de idade, todos os quartos eram ordenhados e os bezerros tinham acesso às mães por um período de 30 minutos para mamar apenas o leite residual. Posteriormente, eram encaminhados aos piquetes, formados por braquiária (Brachiaria decumbens e Brachiaria brizantha), com água e sal mineral ad libitum e, durante o inverno, recebiam silagem de milho (Zea mays, Z.).

Foram analisadas a produção de leite total, a produção média diária de leite, a duração da lactação e a incidência de mastite. Nos bezerros, foram analisados o ganho de peso diário e o peso corporal no momento da desmama. A condição e o peso corporal das vacas foram analisados verificando-se a variação do peso e do escore corporal das vacas ao parto e no $1 \underline{\underline{o}}$ e $2 \underline{\underline{o}}$ cios.

Para avaliar a produção de leite, a duração da lactação e a produção média diária de leite durante a lactação, foram realizados controles leiteiros a cada sete dias após o parto.

As vacas foram pesadas e avaliadas quanto ao escore corporal no dia do parto e a cada 28 dias a partir de sua ocorrência. A avaliação do escore corporal seguiu a escala de 3 a 5 pontos ( 3 - baixo e 5 -alto), conforme Ruas (2000). Os bezerros foram pesados no dia do nascimento, a cada 28 dias e no momento da desmama, aos 284 dias.

Para as variáveis quantitativas (produção de leite total, duração da lactação, produção média diária de leite, incidência de mastite, variação do peso corporal, variação do escore corporal, ganho de peso diário do bezerro e peso dos bezerros à desmama), aplicou-se a análise de variância, considerando-se apenas o efeito do tratamento (inteiramente casualizado), efetuando-se as comparações entre as médias pelo teste Student-Newman-Keuls (SNK). O comportamento da curva da lactação foi submetido à análise de regressão, determinando-se a curva que melhor se ajustou a cada tratamento (Conover, 1980; Snedcor \& Cochran, 1980). As análises foram feitas utilizando-se o programa SAEG 8.1 (UFV, 2001). 


\section{Resultados e Discussão}

Na Tabela 2 são apresentados os dados referentes ao peso e ao escore da condição corporal no momento do parto dos animais dos grupos experimentais, observando-se homogeneidade $(\mathrm{P}>0,05)$ entre eles, com as vacas parindo em boa condição corporal.

Os resultados referentes à variação do número de ordenhas realizadas diariamente são apresentados na Tabela 3. A adoção de uma ordenha a mais, diariamente, continuamente ou de forma alternada, promoveu maior produção $(\mathrm{P}<0,05)$ de leite no final da lactação, em relação à ordenha diária.

A utilização de duas ordenhas diárias durante toda a lactação resultou em aumento de $24,54 \%$ na produção total de leite no final da lactação e em torno de $699,9 \mathrm{~kg}$ de leite a mais em relação à utilização de apenas uma ordenha diária. A adoção de uma ou duas ordenhas diárias, de forma alternada, proporcionou aumento de $19,53 \%$ na produção de leite total no final da lactação (aproximadamente 522,4 kg de leite a mais) em relação ao grupo submetido a apenas uma ordenha diária. Comparando-se o sistema de duas ordenhas diárias durante toda a lactação com duas ordenhas diárias de forma alternada, verificou-se aumento de $6,22 \%$ na produção, cerca de $177,5 \mathrm{~kg}$ de leite a mais no sistema contínuo (Tabela 3).

Segundo Knight \& Dewhurst (1994), a produção de leite e a freqüência de ordenhas estão correlacionadas positivamente. $\mathrm{O}$ aumento de $24,54 \%$ observado na produção de leite foi semelhante ao relatado por Knight \& Dewhurst
(1994) e Bar Peled et al. (1995), que observaram acréscimos, respectivamente, de 25 e $20 \%$, quando aumentaram as ordenhas de duas para três. A curva de produção de leite durante a lactação foi avaliada com base nas pesagens de leite a cada 14 dias, efetuando-se comparações das médias entre os grupos a cada avaliação e na média geral, conforme apresentado na Tabela 4. A produção média diária de leite e a produção média foram influenciadas $(\mathrm{P}<0,05)$ pelo número de ordenhas a partir do 49o dia de lactação; quando a realização de duas ordenhas diárias promoveu maior produção de leite $(\mathrm{P}<0,05)$ a uma única ordenha diária. Na presença de duas ordenhas diárias, a produção do grupo II igualou-se $(\mathrm{P}>0,05)$ à do grupo III e foi superior $(\mathrm{P}<0,05)$ à do grupo I. Entretanto, quando da adoção de apenas uma ordenha no grupo II, na maioria das vezes, houve declínio na produção de leite, de forma que os valores apresentaram-se similares $(\mathrm{P}>0,05)$ aos do grupo I.

A produção média diária de leite quando da utilização de uma ou duas ordenhas de forma alternada não diferiu $(\mathrm{P}>0,05)$ da produção no sistema de duas ordenhas diárias, de forma contínua.

Neste experimento, a produção de leite foi semelhante até 49 dias para as vacas ordenhadas uma ou duas vezes ao dia. Após 49 dias, vacas ordenhadas duas vezes ao dia produziram mais leite que aquelas ordenhas uma vez ao dia (Tabela 4). Amos et al. (1985), por sua vez, observaram aumento da produção de leite a partir dos 42 dias com o aumento do número de ordenhas diária.

Tabela 2 - Peso médio $(\mathrm{kg})$ e escore corporal ao parto de vacas mestiças Holandês-Zebu submetidas a diferentes manejos de ordenha Table 2 - Average weight $(\mathrm{kg})$ and body condition score at calving of crossbred cows (Holstein-Zebu) submitted to different milking management

\begin{tabular}{llcc}
$\begin{array}{l}\text { Grupos experimentais } \\
\text { Experimental groups }\end{array}$ & $\mathrm{n}$ & $\begin{array}{c}\text { Peso médio (kg) } \\
\text { Average weight (kg) }\end{array}$ & $\begin{array}{c}\text { Escore da condição corporal } \\
\text { Body condition score }\end{array}$ \\
\hline $\begin{array}{l}\text { GI - uma ordenha ao dia } \\
\text { GI - milking once a day }\end{array}$ & 21 & $484,7 \pm 38,0$ \\
GII - duas ordenhas ao dia & 21 & $496,3 \pm 67,9$ \\
$\begin{array}{l}\text { GII - milking twice a day } \\
\text { GIII - uma ou duas ordenhas ao dia }\end{array}$ & 21 & $497,7 \pm 44,9$ \\
GIII - milking once or twice a day & & $3,7 \pm 0,4$
\end{tabular}

Tabela 3 - Produção total de leite $(\mathrm{kg})$ de vacas mestiças Holandês-Zebu submetidas a diferentes manejos de ordenha Table 3 - Total milk yield $(\mathrm{kg})$ of crossbred cows (Holstein-Zebu) submitted to different milking management

\begin{tabular}{llcc}
\hline $\begin{array}{l}\text { Grupo experimental } \\
\text { Experimental group }\end{array}$ & $\mathrm{n}$ & $\begin{array}{c}\text { Média (kg) } \\
\text { Average (kg) }\end{array}$ & $2.151,7^{\mathrm{b}}$ \\
\hline GI - uma ordenha ao dia & 21 & $2.851,6^{\mathrm{a}}$ & 517,7 \\
GI - milking once a day & & & \\
GII - duas ordenhas ao dia & 21 & $2.674,0^{\mathrm{a}}$ \\
GII - milking twice a day & 21 & 637,4 \\
GIII - uma ou duas ordenhas ao dia & & 614,0 \\
GIII - milking once or twice a day &
\end{tabular}

\footnotetext{
a,b Letras minúsculas diferentes na mesma coluna diferem $(P<0,05)$ pelo teste $S N K$.

$a, b$ Different small letters in the same collumn differ $(P<0.05)$ according to SNK test.
} 
A duração da lactação não foi influenciada $(\mathrm{P}>0,05)$ pelo número de ordenhas diárias (Tabela 5). Ressalta-se que a adoção de uma única ordenha durante toda a lactação não interferiu na duração da lactação, contrariando os resultados obtidos por Knight \& Dewhurst (1994), que relataram menor duração da lactação. A explicação dos autores para este fato é que, no início da lactação, há maior atividade da glândula e, conseqüentemente, maior produção de leite.

$\mathrm{Na}$ Tabela 6 são apresentados os dados referentes à incidência de mastite, que não foi influenciada $(\mathrm{P}>0,05)$ pela redução do número de ordenhas por dia.

Na Nova Zelândia, é comum a adoção do manejo de uma ordenha no período final da lactação, visando reduzir os custos de produção. Entretanto, Kelly et al. (1998) não recomendam a adoção deste manejo, em razão de seu efeito na qualidade do leite, aumentando o número de células somáticas e de polimorfo-mononucleares. Porém, neste trabalho, a adoção de uma ordenha não prejudicou a saúde da glândula mamária, o que pode ser justificado pela amamentação do bezerro após o término da ordenha. Combellas et al. (2003) afirmaram que o contato com a mãe após a ordenha permite ao bezerros mamar o leite residual, reduzindo a quantidade de microrganismos ali presentes, evitando a ocorrência de processos inflamatórios na glândula mamária.

Não houve diferenças $(\mathrm{P}>0,05)$ entre os três tratamentos quanto ao ganho de peso dos bezerros durante a fase de cria (Tabela 7).

Tabela 4 - Produção média diária de leite $(\mathrm{kg})$ durante a lactação de vacas mestiças Holandês-Zebu submetidas a diferentes manejos de ordenha, no período pós-parto

Table 4 - Daily average milk yield $(\mathrm{kg})$ during the lactation of crossbred cows (Holstein-Zebu) submitted to different milking management

\begin{tabular}{|c|c|c|c|c|c|c|c|}
\hline \multirow[t]{2}{*}{$\begin{array}{l}\text { Dias de lactação } \\
\text { Lactation days }\end{array}$} & \multicolumn{2}{|c|}{$\begin{array}{c}\text { GI - uma ordenha } \\
\text { GI - milking once a day }\end{array}$} & \multicolumn{2}{|c|}{$\begin{array}{l}\text { GII - duas ordenhas } \\
\text { GII - milking twice a day }\end{array}$} & \multicolumn{2}{|c|}{$\begin{array}{l}\text { GIII - alternância } \\
\text { GIII - alternation }\end{array}$} & \multirow[t]{2}{*}{$\begin{array}{l}\text { Número deordenhas } \\
\text { Number of milking. }\end{array}$} \\
\hline & $\begin{array}{l}\text { Média* } \\
\text { Mean }\end{array}$ & $\begin{array}{c}\text { Desvio } \\
\text { Deviation }\end{array}$ & $\begin{array}{l}\text { Média } \\
\text { Mean }\end{array}$ & $\begin{array}{c}\text { Desvio } \\
\text { Deviation }\end{array}$ & $\begin{array}{l}\text { Média } \\
\text { Mean }\end{array}$ & $\begin{array}{c}\text { Desvio } \\
\text { Deviation }\end{array}$ & \\
\hline 12 & $9,2^{\mathrm{a}}$ & 2,0 & $11,5^{\mathrm{a}}$ & 3,1 & $12,2^{\mathrm{a}}$ & 3,3 & 2 \\
\hline 23 & $9,4^{\mathrm{a}}$ & 2,6 & $12,7^{\mathrm{a}}$ & 2,6 & $10,0^{\mathrm{a}}$ & 4,6 & 1 \\
\hline 35 & 9,9 & 4,1 & 13,5 & 3,4 & 13,6 & 3,5 & 2 \\
\hline 49 & $8,9^{b}$ & 2,2 & $12,8^{\mathrm{a}}$ & 3,2 & $10,9^{a, b}$ & 3,6 & 1 \\
\hline 63 & $8,8^{b}$ & 2,2 & $12,3^{\mathrm{a}}$ & 3,0 & $12,8^{\mathrm{a}}$ & 3,0 & 2 \\
\hline 77 & $8,8^{\mathrm{b}}$ & 2,9 & $11,9^{\mathrm{a}}$ & 3,2 & $10,0^{\mathrm{a}, \mathrm{b}}$ & 2,2 & 1 \\
\hline 91 & $8,0^{\mathrm{b}}$ & 1,9 & $11,5^{\mathrm{a}}$ & 2,8 & $11,7^{\mathrm{a}}$ & 3,5 & 2 \\
\hline 105 & $7,9^{\mathrm{b}}$ & 2,9 & $11,5^{\mathrm{a}}$ & 3,5 & $9,3^{b}$ & 2,2 & 1 \\
\hline 119 & $8,2^{b}$ & 2,0 & $11,0^{\mathrm{a}}$ & 3,2 & $11,0^{\mathrm{a}}$ & 2,6 & 2 \\
\hline 133 & $7,8 \mathrm{~b}$ & 2,6 & $11,1^{\mathrm{a}}$ & 3,0 & $8,2^{b}$ & 2,7 & 1 \\
\hline 147 & $7,6^{b}$ & 2,2 & $11,2^{\mathrm{a}}$ & 3,0 & $10,3^{\mathrm{a}}$ & 2,8 & 2 \\
\hline 161 & $7,8 \mathrm{~b}$ & 2,5 & $10,7^{\mathrm{a}}$ & 2,7 & $8,2^{b}$ & 2,0 & 1 \\
\hline 174 & $6,9^{b}$ & 2,1 & $11,1^{\mathrm{a}}$ & 3,0 & $10,2^{\mathrm{a}}$ & 2,3 & 2 \\
\hline 188 & $6,8^{b}$ & 1,8 & $10,3^{\mathrm{a}}$ & 3,3 & $7,4^{b}$ & 1,8 & 1 \\
\hline 202 & $6,4^{b}$ & 1,9 & $10,3^{\mathrm{a}}$ & 2,8 & $9,0^{\mathrm{a}}$ & 2,1 & 2 \\
\hline 216 & $6,3^{b}$ & 1,9 & $9,9^{\mathrm{a}}$ & 2,3 & $7,1^{\mathrm{b}}$ & 1,5 & 1 \\
\hline 230 & $5,8^{\mathrm{c}}$ & 1,8 & $9,6^{\mathrm{a}}$ & 2,8 & $7,8^{b}$ & 3,1 & 2 \\
\hline 243 & $6,1^{b}$ & 2,3 & $9,0^{\mathrm{a}}$ & 2,8 & $7,6^{\mathrm{a}, \mathrm{b}}$ & 2,2 & 1 \\
\hline 258 & $5,8^{b}$ & 1,9 & $8,6^{\mathrm{a}}$ & 2,4 & $7,6^{\mathrm{a}}$ & 2,4 & 2 \\
\hline 271 & $5,4^{b}$ & 2,0 & $8,7^{\mathrm{a}}$ & 1,8 & $6,7^{\mathrm{b}}$ & 1,3 & 1 \\
\hline 287 & 5,5 & 1,5 & 6,8 & 2,4 & & & \\
\hline Média & $7,4^{b}$ & 1,6 & $10,1^{\mathrm{a}}$ & 2,6 & $9,7^{\mathrm{a}}$ & 2,0 & \\
\hline Average & & & & & & & \\
\hline
\end{tabular}

a,b Letras minúsculas diferentes na mesma linha diferem $(P<0,05)$ pelo teste SNK.

$a, b$ Different small letters in the same row differ $(P<0.05)$ according to SNK test.

* $\mathrm{kg}$ de leite/vaca/dia ( $\mathrm{kg}$ of milk/cow/day).

Tabela 5 - Duração da lactação (dias) de vacas mestiças Holandês-Zebu submetidas a diferentes manejos de ordenha Table 5 - Lenght of lactation (days) of crossbred cows (Holstein-Zebu) submitted to different milking management

\begin{tabular}{llcc}
\hline $\begin{array}{l}\text { Grupo experimental } \\
\text { Experimental group }\end{array}$ & $\mathrm{n}$ & $\begin{array}{c}\text { Média (kg) } \\
\text { Mean (kg) }\end{array}$ & 288,7 \\
\hline GI - uma ordenha ao dia & 21 & 286,5 \\
$\begin{array}{l}\text { GI - milking once a day } \\
\text { GII - duas ordenhas ao dia }\end{array}$ & 21 & 34,0 \\
GII - milking twice a day & 21 & 276,4 \\
GIII - uma ou duas ordenhas ao dia & & 40,1 \\
GIII - milking once or twice a day & &
\end{tabular}


Neste experimento, nos primeiros três meses da lactação, deixou-se de ordenhar um teto para que os bezerros mamassem após a ordenha. Após esse período, todos os tetos foram ordenhados, permitindo que os bezerros mamassem apenas o leite residual. Assim, nos grupos envolvendo vacas ordenhadas duas vezes ao dia, os bezerros tinham acesso à maior quantidade de leite residual, porém, a maior ingestão de leite pelo bezerro não resultou $(\mathrm{P}>0,05) \mathrm{em}$ maior ganho de peso, pois provavelmente a quantidade de leite residual era baixa. Desse modo, o peso corporal dos

Tabela 6 - Incidência de mastite avaliada por escore de CMT durante a lactação em vacas mestiças Holandês-Zebu submetidas a diferentes manejos de ordenha

Table 6 - Incidence of mastitis using the CMT score during the lactation of crossbred cows (Holstein-Zebu) submitted to different milking management

\begin{tabular}{|c|c|c|c|c|c|c|}
\hline \multirow[b]{2}{*}{$\begin{array}{l}\text { Dias pós-parto } \\
\text { Days of postpartum }\end{array}$} & \multicolumn{2}{|c|}{$\begin{array}{c}\text { GI - uma ordenha } \\
\text { GI - milking once a day }\end{array}$} & \multicolumn{2}{|c|}{$\begin{array}{c}\text { GII - duas ordenhas } \\
\text { GII - milking twice a day }\end{array}$} & \multicolumn{2}{|c|}{$\begin{array}{l}\text { GIII - alternância } \\
\text { GIII - alternation }\end{array}$} \\
\hline & $\begin{array}{l}\text { Média } \\
\text { Mean }\end{array}$ & $\begin{array}{c}\text { Desvio } \\
\text { Deviation }\end{array}$ & $\begin{array}{l}\text { Média } \\
\text { Mean }\end{array}$ & $\begin{array}{c}\text { Desvio } \\
\text { Deviation }\end{array}$ & $\begin{array}{l}\text { Média } \\
\text { Mean }\end{array}$ & $\begin{array}{c}\text { Desvio } \\
\text { Deviation }\end{array}$ \\
\hline 17 & 4,0 & 0,0 & 4,0 & 0,0 & 4,0 & 0,0 \\
\hline 50 & 4,0 & 0,0 & 4,0 & 0,0 & 4,2 & 0,6 \\
\hline 78 & 3,9 & 0,5 & 4,0 & 0,0 & 4,1 & 0,2 \\
\hline 106 & 4,1 & 0,4 & 4,0 & 0,0 & 4,0 & 0,0 \\
\hline 134 & 3,9 & 0,4 & 4,0 & 0,2 & 4,1 & 0,3 \\
\hline 162 & 4,2 & 0,6 & 4,0 & 0,2 & 4,4 & 1,2 \\
\hline 190 & 4,3 & 0,7 & 4,0 & 0,2 & 4,3 & 0,9 \\
\hline 218 & 4,1 & 0,5 & 4,2 & 0,5 & 4,3 & 0,9 \\
\hline 246 & 4,4 & 1,1 & 4,1 & 0,2 & 4,2 & 1,0 \\
\hline 274 & 4,0 & 0,0 & 4,4 & 1,2 & 4,9 & 1,8 \\
\hline Média & 4,1 & 0,4 & 4,1 & 0,1 & 4,3 & 0,4 \\
\hline Average & & & & & & \\
\hline
\end{tabular}

Tabela 7 - Ganho de peso $(\mathrm{kg})$ de bezerros mestiços submetidos a diferentes manejos de ordenha

Table 7 - Weight gain $(\mathrm{kg})$ of crossbred calves submitted to different milking management

\begin{tabular}{|c|c|c|c|c|c|c|}
\hline \multirow[t]{2}{*}{$\begin{array}{l}\text { Peso ao nascer e ganho de peso }(\mathrm{kg}) \\
\text { Weight at calving and weight gain }\end{array}$} & \multicolumn{2}{|c|}{$\begin{array}{l}\text { GI - uma ordenha } \\
\text { GI - milking once a day }\end{array}$} & \multicolumn{2}{|c|}{$\begin{array}{l}\text { GII - duas ordenhas } \\
\text { GII - milking twice a day }\end{array}$} & \multicolumn{2}{|c|}{$\begin{array}{l}\text { GIII - alternância } \\
\text { GIII - alternation }\end{array}$} \\
\hline & $\begin{array}{l}\text { Média* } \\
\text { Mean }\end{array}$ & $\begin{array}{l}\text { Desvio } \\
\text { Deviation }\end{array}$ & $\begin{array}{l}\text { Média } \\
\text { Mean }\end{array}$ & $\begin{array}{l}\text { Desvio } \\
\text { Deviation }\end{array}$ & $\begin{array}{l}\text { Média } \\
\text { Mean }\end{array}$ & $\begin{array}{l}\text { Desvio } \\
\text { Deviation }\end{array}$ \\
\hline $\begin{array}{l}\text { Peso ao nascer } \\
\text { Weight at calving }\end{array}$ & $31,7^{b}$ & 4,3 & $36,57^{a, b}$ & 6,3 & $33,29 \mathrm{~b}$ & 3,84 \\
\hline $\begin{array}{l}\text { Ganho até os } 20 \text { dias } \\
\text { Weight gain until } 20 \text { days }\end{array}$ & $9,7^{\mathrm{a}}$ & 3,1 & $10,0^{\mathrm{a}}$ & 5,8 & $11,1^{\mathrm{a}}$ & 5,18 \\
\hline $\begin{array}{l}\text { Ganho até os } 49 \text { dias } \\
\text { Weight gain until } 49 \text { days }\end{array}$ & $8,9^{\mathrm{a}}$ & 4,5 & $10,6^{\mathrm{a}}$ & 5,7 & $10,2^{\mathrm{a}}$ & 5,91 \\
\hline $\begin{array}{l}\text { Ganho até os } 76 \text { dias } \\
\text { Weight gain until } 76 \text { days }\end{array}$ & $8,8^{\mathrm{a}}$ & 7,6 & $9,3^{\mathrm{a}}$ & 6,3 & $5,2^{\mathrm{a}}$ & 6,0 \\
\hline $\begin{array}{l}\text { Ganho até os } 103 \text { dias } \\
\text { Weight gain until } 103 \text { days }\end{array}$ & $11,2^{\mathrm{a}}$ & 7,3 & $11,9^{\mathrm{a}}$ & 6,0 & $12,0^{\mathrm{a}}$ & 7,1 \\
\hline $\begin{array}{l}\text { Ganho até os } 128 \text { dias } \\
\text { Weight gain until } 128 \text { days }\end{array}$ & $9,0^{\mathrm{a}}$ & 6,1 & $12,0^{\mathrm{a}}$ & 5,0 & $12,6^{\mathrm{a}}$ & 6,4 \\
\hline $\begin{array}{l}\text { Ganho até os } 152 \text { dias } \\
\text { Weight gain until } 152 \text { days }\end{array}$ & $7,6^{\mathrm{a}}$ & 5,0 & $10,8^{\mathrm{a}}$ & 4,3 & $11,3^{\mathrm{a}}$ & 5,3 \\
\hline $\begin{array}{l}\text { Ganho até os } 176 \text { dias } \\
\text { Weight gain until } 176 \text { days }\end{array}$ & $13,4^{\mathrm{a}}$ & 6,7 & $12,0^{\mathrm{a}}$ & 7,7 & $11,6^{\mathrm{a}}$ & 7,5 \\
\hline $\begin{array}{l}\text { Ganho até os } 199 \text { dias } \\
\text { Weight gain until } 199 \text { days }\end{array}$ & $9,3^{\mathrm{a}}$ & 4,9 & $14,0^{\mathrm{a}}$ & 6,6 & $12,7^{\mathrm{a}}$ & 7,9 \\
\hline $\begin{array}{l}\text { Ganho até os } 222 \text { dias } \\
\text { Weight gain until } 222 \text { days }\end{array}$ & $14,8^{\mathrm{a}}$ & 8,7 & $16,7^{\mathrm{a}}$ & 7,0 & $15,2^{\mathrm{a}}$ & 7,6 \\
\hline $\begin{array}{l}\text { Ganho até os } 247 \text { dias } \\
\text { Weight gain until } 247 \text { days }\end{array}$ & $13,4^{\mathrm{a}}$ & 8,2 & $10,5^{\mathrm{a}}$ & 8,0 & $12,6^{\mathrm{a}}$ & 7,3 \\
\hline $\begin{array}{l}\text { Ganho até os } 273 \text { dias } \\
\text { Weight gain until } 273 \text { days }\end{array}$ & $10,5^{\mathrm{a}}$ & 6,4 & $14,3^{\mathrm{a}}$ & 13,9 & $13,1^{\mathrm{a}}$ & 6,5 \\
\hline $\begin{array}{l}\text { Ganho até os } 301 \text { dias } \\
\text { Weight gain until } 301 \text { days }\end{array}$ & $17,6^{\mathrm{a}}$ & 9,8 & $16,3^{\mathrm{a}}$ & 9,8 & $15,8^{\mathrm{a}}$ & 9,0 \\
\hline $\begin{array}{l}\text { Ganho de peso total } \\
\text { All weight gain }\end{array}$ & $129,4^{\mathrm{a}}$ & 30,5 & $143,3^{\mathrm{a}}$ & 25,6 & $133,6^{\mathrm{a}}$ & 33,5 \\
\hline
\end{tabular}

a,b Letras minúsculas diferentes na mesma linha diferem $(P<0,05)$ pelo teste SNK.

$a, b$ Different small letters in the same row differ $(P<0.05)$ according to SNK test. 
Tabela 8 - Peso corporal $(\mathrm{kg})$ de bezerros mestiços à desmama (284 dias de idade) submetidos a diferentes manejos de ordenha Table 8 - Body weight $(\mathrm{kg})$ of crossbred calves weaned at 284 days of age submitted to different milking management

\begin{tabular}{|c|c|c|c|}
\hline $\begin{array}{l}\text { Grupos experimentais } \\
\text { Experimental groups }\end{array}$ & $\mathrm{n}$ & $\begin{array}{c}\text { Média }(\mathrm{kg}) \\
\text { Mean }(\mathrm{kg})\end{array}$ & $\begin{array}{l}\text { Desvio-padrão } \\
\text { Standard deviation }\end{array}$ \\
\hline $\begin{array}{l}\text { GI - uma ordenha ao dia } \\
\text { GI - milking once a day }\end{array}$ & 21 & 161,1 & 32,6 \\
\hline $\begin{array}{l}\text { GII - duas ordenhas ao dia } \\
\text { GII - milking twice a day }\end{array}$ & 21 & 179,9 & 25,6 \\
\hline $\begin{array}{l}\text { GIII - uma ou duas ordenhas ao dia } \\
\text { GIII - milking once and twice a day }\end{array}$ & 20 & 166,9 & 34,9 \\
\hline
\end{tabular}

bezerros aos 284 dias de vida (quando da desmama) não diferiu ( $\mathrm{P}>0,05)$ entre os grupos experimentais (Tabela 8 ). Segundo Campos et al. (1993b), o consumo de leite pelo bezerro é o maior determinante de seu ganho de peso, o que não foi confirmado neste trabalho.

\section{Conclusões}

A prática de duas ordenhas diárias, em vez de uma, aumenta em 24,54\%a produção de leite. A utilização de uma e duas ordenhas diárias, de forma alternada, em relação a uma de forma contínua, aumenta em $19,53 \%$ a produção de leite. A incidência da mastite não é influenciada pela redução do número diário de ordenhas. O desempenho dos bezerros não é alterado pelas freqüências de amamentação.

\section{Literatura Citada}

AMOS, H.E.; KISER, T.; LOEWENSTEIN, M. Influence of milking frequency on productive and reproductive efficiencies of dairy cows. Journal of Dairy Science, v.68, n.3, p.732-739, 1985.

BAR-PELED, U.; MALTZ, E.; BRUCKENTAL, I. et al. Relationship between frequent milking or suckling in early lactation and milk production of high producing dairy cows. Journal of Dairy Science, v.78, n.12, p.2726-2736, 1995.

CAMPOS, O.F.; LIZIEIRE, R.S.; DERESZ, F. et al. Sistemas de aleitamento natural controlado ou artificial. I. Efeitos na performance de vacas mestiças holandês-zebu. Revista da Sociedade Brasileira de Zootecnia, v.22, n.3, p.413-423, 1993a.

CAMPOS, O.F.; LIZIEIRE, R.S.; DERESZ, F. et al. Sistemas de aleitamento natural controlado ou artificial. II. Efeitos na performance de bezerros mestiços holandês-zebu. Revista da Sociedade Brasileira de Zootecnia, v.22, n.3, p.423-431, 1993b.

COMBELLAS, J.; TESORERO, M.; GABALDÓN, L. Effect of calf stimulation during milking on milk yield and fat content Bos indicus x Bos taurus cows. Livestock Production Science, v.79, n.2-3, p.227-232, 2003.

CONOVER, W.J. Practical nonparametric statistics. New York: Wiley, 1980. 493p.

DePETERS, E.J.; SMITH, N.E.; ACEDO-RICO, J. Three or two times daily milking of older cows and first lactation cows for entire lactations. Journal of Dairy Science, v.68, n.1, p.123132,1985

ERDMAN, R.A.; VARNER, M. Fixed yield responses to increased milking frequency. Journal of Dairy Science, v.78, n.5, p.1999-2003, 1995 .
HILLERTON, J.E.; KNIGHT, C.H.; TURVEY, A. et al. Milk yield and mammary function in dairy cows milked four times daily. Journal of Dairy Research, v.57, n.3, p.285-294, 1990.

KELLY, A.L.; REID, S.; JOYCE, P. et al. Effect of decreased milking frequency of cows in late lactation on milk somatic cell count, polymorphonuclear leucocyte numbers, composition and proteolytic activity. Journal of Dairy Research, v.65, n.3, p.365-373, 1998.

KNIGHT, C.H.; DEWHURST, R.J. Once daily milking of dairy cows: relationship between yield loss and cisternal milk storage. Journal of Dairy Research, v.61, n.4, p.441-449, 1994.

KNIGHT, C.H.; HILLERTON, J.E.; KERR, M.A. et al. Separate and additive stimulation of bovine milk yield by the local and systemic galactopoietic stimuli of frequent milking and growth hormone. Journal of Dairy Research, v.59, n.3, p.243-252, 1992.

RADOSTITIS, O.M.; LESLIE, K.E.; FETROW, J. Mastits control in dairy herds. In: Head health food animal production medicine. 2.ed. Philadelphia: Saunders, 1994. 276p.

RUAS, J.R.M.; TORRES, C.A.A.; BORGES, L.E. et al. Concentrações plasmáticas de colesterol, glicose e uréia em vacas zebuínas em relação à condição corporal e ao status reprodutivo. Revista Brasileira de Zootecnia, v.29, n.6, p.2036-2042, 2000 (supl. 1).

SCHALM, O.W.; NOORLANDER, D.O. Experimental and observations leading to developing of California Mastitis Test. Journal of the American Veterinary Medical Association, v.139, n.2, p.199-204, 1957.

SNEDCOR, G.W.; COCHRAN, W.G. Statistical methods. Ames: Iowa State Universty, 1980. 505p.

STELWAGEN, K.; KNIGHT, C.H. Effect of unilateral once or twice daily milking of cows on milk yield and udder characteristics in early and late lactation. Journal of Dairy Research, v. 64, n.7, p.487-494, 1997.

STELWAGEN, K.; POLITIS, I.; WHITE, J.H. et al. Effect of milking frequency and somatotropin on the activity of plasminogen activator, plasminogen, and plasmina in bovine milk. Journal of Dairy Science, v.77, n.12, p.3577-3583, 1994.

UGARTE, J.; PRESTON, T.R. Rearing dairy calves by restricted suckling. 1. Effect of suckling once or twicw daily on milk production and calf growth. Revista Cubana Ciência Agrícola (Eng. Ed.), v.6, n.2, p.173- 182, 1972.

UNIVERSIDADE FEDERAL DE VIÇOSA - UFV. Sistema para Análises Estatísticas e Genética - SAEG. versão 8.1. Viçosa, MG: Fundação Arthur Bernardes, 2001. 